\title{
Comunidades epifíticas em citros associadas ao huanglongbing em áreas com e sem aplicação de biofertilizante
}

\author{
Epiphytic communities associated with citrus huanglongbing in areas with and without \\ application of biofertilizer
}

Comunidades epífitas en cítricos asociadas con huanglongbing en áreas con

y sin aplicación de biofertilizante

\author{
Rodrigo Domiciano Marques \\ ORCID: https://orcid.org/0000-0002-5933-9776 \\ Universidade Estadual do Norte do Paraná, Brasil \\ E-mail: rodrigodmarques592@gmail.com \\ Paula Fernanda de Azevedo \\ ORCID: https://orcid.org/0000-0003-4327-6800 \\ Universidade Estadual do Norte do Paraná, Brasil \\ E-mail: paula.fer.azevedo@hotmail.com \\ Aline Vanessa Sauer \\ ORCID: https://orcid.org/0000-0003-3164-9710 \\ Universidade Estadual do Norte do Paraná, Brasil \\ E-mail: aline.sauer@kroton.com.br \\ Leopoldo Sussumu Matsumoto \\ ORCID: https://orcid.org/0000-0001-5102-545X \\ Universidade Estadual do Norte do Paraná, Brasil \\ E-mail: leopoldo@uenp.edu.br
}

\begin{abstract}
Resumo
Huanglongbing (HLB) é a doença mais grave para a citricultura. Plantas pouco afetadas por patógenos podem ser explicados pelas interações entre populações microbianas e plantas. A reestruturação de comunidades pode ser feita pelo uso de biofertilizantes, com potencial de suprimir doenças por meio do estímulo de microrganismos benéficos. Assim, o objetivo deste trabalho foi avaliar as comunidades epifíticas de citros associadas ao HLB em áreas com e sem aplicação de biofertilizante. Amostras de folhas foram coletadas aleatoriamente de árvores sintomáticas, assintomáticas e saudáveis. Fungos totais, fixadores de nitrogênio e bactérias totais foram avaliados pela contagem de unidades formadoras de colônia (UFC) em meio de cultura. Os dados foram tratados em esquema fatorial 2x3, submetidos à análise de variância e as médias foram comparadas por teste de Tukey $(\mathrm{p}<0,05)$. O número de bactérias totais foi expressivamente maior na área com aplicação de biofertilizante, seja em plantas sadias, assintomáticas ou sintomáticas. A aplicação de biofertilizante é capaz de aumentar a comunidade bacteriana epifítica em citros.
\end{abstract}

Palavras-chave: Bactérias totais; Candidatus Liberibacter spp.; Fixadores de nitrogênio; Fungos totais.

\begin{abstract}
Huanglongbing (HLB) is the most serious disease for citrus. Plants little affected by pathogens can be explained by interactions between microbial populations and plants. The restructuring of communities can be made by the use of biofertilizers, with the potential to suppress disease by stimulating beneficial microorganisms. The objective of this study was to evaluate the epiphytic communities of citrus associated with HLB in areas with and without application of biofertilizers. Leaf samples were collected randomly from symptomatic, asymptomatic and healthy trees. Total fungi, nitrogen fixers and total bacteria were evaluated by counting colony forming units (CFU) on culture medium . The data were analyzed in a $2 \times 3$ factorial, submitted to analysis of variance and means were compared by Tukey test ( $\mathrm{p}<0.05)$. The number of total bacteria was expressively higher in the area with the application of biofertilizer, either in healthy, asymptomatic or symptomatic plants. The application of biofertilizer is able to increase the epiphytic bacterial community in citrus.
\end{abstract}

Keywords: Candidatus Liberibacter spp; Nitrogen fixers; Total bacteria; Total fungi.

\section{Resumen}

Huanglongbing (HLB) es la enfermedad más grave de los cítricos. Las plantas poco afectadas por patógenos pueden explicarse por las interacciones entre las poblaciones microbianas y las plantas. La reestructuración de las comunidades se puede realizar mediante el uso de biofertilizantes, con el potencial de suprimir enfermidades mediante 
la estimulación de microorganismos beneficiosos. Así, el objetivo de este trabajo fue evaluar las comunidades epífitas de cítricos asociadas al HLB en áreas con y sin aplicación de biofertilizantes. Se recolectaron muestras de hojas al azar de árboles sintomáticos, asintomáticos y sanos. Los hongos totales, los fijadores de nitrógeno y las bacterias totales se evaluaron contando las unidades formadoras de colonias (UFC). Los datos se trataron en un esquema factorial $2 \times 3$, se sometieron a análisis de varianza y las medias se compararon mediante la prueba de Tukey ( $\mathrm{p}<0.05)$. El número de bacterias totales fue significativamente mayor en el área con aplicación de biofertilizante, ya sea en plantas sanas, asintomáticas o sintomáticas. La aplicación de biofertilizantes es capaz de incrementar la comunidad bacteriana epífita en cítricos.

Palabras clave: Bacterias totales; Candidatus Liberibacter spp.; Fijadores de nitrógeno; Hongos totales.

\section{Introdução}

Huanglongbing (HLB), anteriormente conhecido como greening dos citros, é a doença mais grave para a citricultura, atingindo várias áreas produtoras do mundo (Ásia, América do Norte, América do Sul e África) (Trivedi et al., 2012). Inicialmente, HLB foi traduzido como "doença do dragão amarelo" e posteriormente corrigido para "doença dos ramos amarelados". Apesar do sul da China ser considerado a origem da HLB, relatos mais antigos descrevem a mesma sintomatologia em áreas na Índia (Gottwald et al., 2007).

O HLB está relacionado a Candidatus Liberibacter spp., bactérias fastidiosas, limitadas ao floema, que ainda não são cultiváveis artificialmente. Dentre as espécies do gênero $\mathrm{Ca}$. Liberibacter, $\mathrm{Ca}$. Liberibacter asiaticus (Las) é a de maior ocorrência, em detrimento de $\mathrm{Ca}$. Liberibacter americanus (Lam) e $\mathrm{Ca}$. Liberibacter africanus (Kim et al., 2009).

Por muito tempo, a HLB era tida como deficiência nutricional ou causada por alagamento, até que foi observada a transmissão via enxertia. Hoje, conhecidamente, além da enxertia, a HLB se dissemina através de vetores, principalmente o psilídeo Diaphorina citri, associado à espécie Candidatus Liberibacter asiaticus (Gottwald et al., 2007).

A infecção relacionada ao HLB causa efeitos na expressão de 624 genes de laranja (Citrus sinensis), os quais estão associados a funções como metabolismo de açúcar, defesa da planta, resposta metabólica a estresses ambientais, metabolismo de proteínas, transporte e energia (Kim et al., 2009).

Anatomicamente, ocorre a ruptura do floema, acúmulo de sacarose e bloqueio de vasos condutores (Kim et al., 2009), acarretando sintomas foliares como o aspecto mosqueado em tons de verde e amarelo (Feichtenberger et al., 2005). Frutos doentes são pequenos, defeituosos, assimétricos e de coloração externa irregular, derivados da maturação desigual, originando o termo greening (Feichtenberger et al., 2005; Gottwald et al., 2007).

Não há método de controle curativo para HLB em pomares e fontes de resistência ainda estão sob estudos, logo evitar a disseminação da doença é a medida mais eficaz de controle disponível, uma vez que todos os genótipos utilizados na citricultura são susceptíveis a $\mathrm{Ca}$. Liberibacter asiaticus e $\mathrm{Ca}$. Liberibacter americanus e ao vetor Diaphorina citri. (Belasque Junior et al., 2010; Boscariol-Camargo et al., 2010; Mourão Filho et al., 2010; Bassanezi et al., 2020).

O psilídeo D. citri, ao sugar seiva de uma árvore infectada, leva de 15-30 minutos a cinco horas para tornar-se contaminado, e passa a ser vetor de transmissão por toda sua vida (Gottwald et al., 2007). O controle desse vetor reduz a população de insetos infectivos e a chance de que ninfas (aquisição) e adultos (aquisição e transmissão) se alimentem de árvores doentes (Belasque Junior et al., 2010).

A diagnose baseada unicamente na inspeção visual das áreas depende de mão de obra treinada, e pode ser dificultada devida à sazonalidade das manchas amareladas típicas, a variações populacionais dos patógenos e sua distribuição irregular nos tecidos vegetais, induzindo a erros que consideram amostras infectadas como HLB-negativas (Gottwald et al., 2007; Belasque Junior et al., 2010; Sauer et al., 2015).

Metodologias que envolvem análise de parâmetros genéticos são uma opção, pois eliminam erros advindos de avaliações subjetivas. A reação em cadeia da polimerase (Polymerase Chain Reaction - PCR) é a técnica mais confiável e sensível como ferramenta de diagnóstico para a detecção de Las. O desenho de primers que amplifiquem regiões do genoma 
altamente repetidas e conservadas, como o gene correspondente à proteína ribossomal $\beta$ operon, é capaz de identificar a presença do patógeno mesmo em concentrações mínimas, como 0,1 pg de DNA alvo (Mahajan et al., 2013).

Mesmo com o uso de técnicas de PCR convencional e PCR quantitativa, resultados mais consistentes são alcançados com coleta de várias folhas em locais diferentes da árvore e em épocas que a doença não se demonstra latente, como no outono para região do Paraná (Sauer et al., 2015).

A presença de Candidatus Liberibacter asiaticus altera significativamente a estrutura e funcionalidade da microbiota associada à rizosfera das plantas infectadas, estabelecendo efeitos sobre a diversidade e abundância de espécies edáficas mesmo sem competição direta (Trivedi et al., 2012).

A interação planta-endofíticos aparenta ser regida por características fenotípicas e genotípicas dos micro-organismos e o genótipo do hospedeiro, como sugerido através da análise de diversidade metabólica e sequenciamento de RNA de diversos isolados de citros, cacau, eucalipto, soja e cana-de-açúcar (Torres et al., 2008). O termo endofítico anteriormente incluía apenas organismos benéficos, contudo, hoje engloba microrganismo que habitam a filosfera, ou seja, toda a porção vegetal acima do solo, de forma benéfica, neutra ou prejudicial. A filosfera, por sua vez, é composta pela comunidade endofítica e epifítica, essa última referente à população externa e superficial (Backman \& Sikora, 2008).

O estudo de comunidades microbianas em sistemas que sofrem impacto antrópico é de extrema importância, como em áreas de agricultura, onde a fauna original é alterada pelo manejo (Chelius \& Triplett, 2001).

A observação de plantas pouco afetadas por patógenos, consideradas escapes, em pomares onde os indivíduos têm o mesmo genótipo, é possivelmente explicado pela natureza das interações entre populações microbianas e as plantas (Araújo et al., 2002). A reestruturação de comunidades pode ser feita pelo uso de biofertilizantes, com potencial de suprimir doenças por meio do estímulo da comunidade microbiana da filosfera, visto que organismos benéficos competem com fitopatógenos por nichos semelhantes (Wu et al., 2009).

Os biofertilizantes de compostagem líquida contínua são obtidos através da fermentação de material orgânico de origem vegetal por microrganismos presentes no rúmen do animal (Medeiros \& Lopes, 2006; Silva et al., 2007). Além da sua atividade como fertilizantes para desenvolvimento vegetal, podem apresentar a capacidade de supressão a alguns patógenos, através do aumento na diversidade e abundância dos microrganismos benéficos, que competem com fitopatógenos por nichos similares, podem produzir moléculas antimicrobianas e apresentam potencial de biocontrole (Araújo et al., 2002; Timmusk et al., 2009, Wu et al., 2009). Resultados positivos foram encontrados no controle de fusariose em banana e pepino (Qiu et al., 2012; Zhang et al., 2014; Shen et al., 2015).

Assim, o objetivo deste trabalho foi avaliar as comunidades epifíticas de folhas de citros associadas ao huanglongbing (HLB) em áreas com e sem aplicação de biofertilizante.

\section{Metodologia}

Os pomares de laranja amostrados estão localizados no município de Paranavaí, estado do Paraná, Brasil. Foram escolhidas duas áreas de coleta, diferindo entre si pelo manejo de aplicação (CB) ou não de biofertilizante (SB). Na área com aplicação de biofertilizante (CB), são realizadas seis pulverizações anuais de $300 \mathrm{~L} \mathrm{ha}^{-1}$.

Amostras de folhas foram coletadas aleatoriamente de árvores de laranja sintomáticas, assintomáticas e saudáveis quanto à presença de Candidatus Liberibacter sp., com 3 repetições. As amostras foram armazenadas em sacos plásticos e transportadas ao laboratório em caixa térmica.

As comunidades de fungos totais, fixadores de nitrogênio e bactérias totais foram avaliadas pela contagem das unidades formadoras de colônia (UFC) nos meios de cultura batata-dextrose-ágar (BDA), NFB (Döbereiner \& Day, 1976), e triptona-soja-ágar (TSA), respectivamente. Para isso, foram selecionadas duas folhas de tamanhos semelhantes por tratamento, 
que foram então lavadas com $50 \mathrm{~mL}$ de solução esterilizada de $\mathrm{NaCl}(0,85 \%)$, sob agitação constante por 2 horas, em erlenmeyer com capacidade de $125 \mathrm{~mL}$, conforme metodologia adaptada a partir de Carvalho et al. (2020).

Após a agitação das amostras, foi pipetada uma alíquota de $100 \mu \mathrm{L}$ e realizada a inoculação em placas de Petri. Os meios de cultura foram mantidos em BOD a $28{ }^{\circ} \mathrm{C}$, até o aparecimento das UFC. Os valores de UFC foram convertidos em logaritmo de base 10, a fim de normalizar os dados, pela fórmula UFClog $=\log _{10}$ (UFC).

$\mathrm{O}$ delineamento foi totalmente casualizado e os dados foram tratados em esquema fatorial $2 \times 3$ (duas áreas e três categorias de plantas), submetidos à análise de variância e as médias foram comparadas por teste de Tukey a $5 \%$ de probabilidade.

\section{Resultados e Discussão}

A comunidade de fungos epifíticos encontrada não apresentou diferenças entre as áreas de cultivo com aplicação de biofertilizante (CB) e sem aplicação de biofertilizante (SB), independentemente da categoria de árvore avaliada, evidenciando que os fungos são pouco influenciados pela aplicação de biofertilizante (Figura 1).

Figura 1. UFClog folha ${ }^{-1}$ de fungos totais, fixadores de nitrogênio e bactérias totais de plantas de citros sadias, assintomáticas e sintomáticas, em áreas com aplicação de biofertilizante (CB) e sem aplicação de biofertilizante (SB).

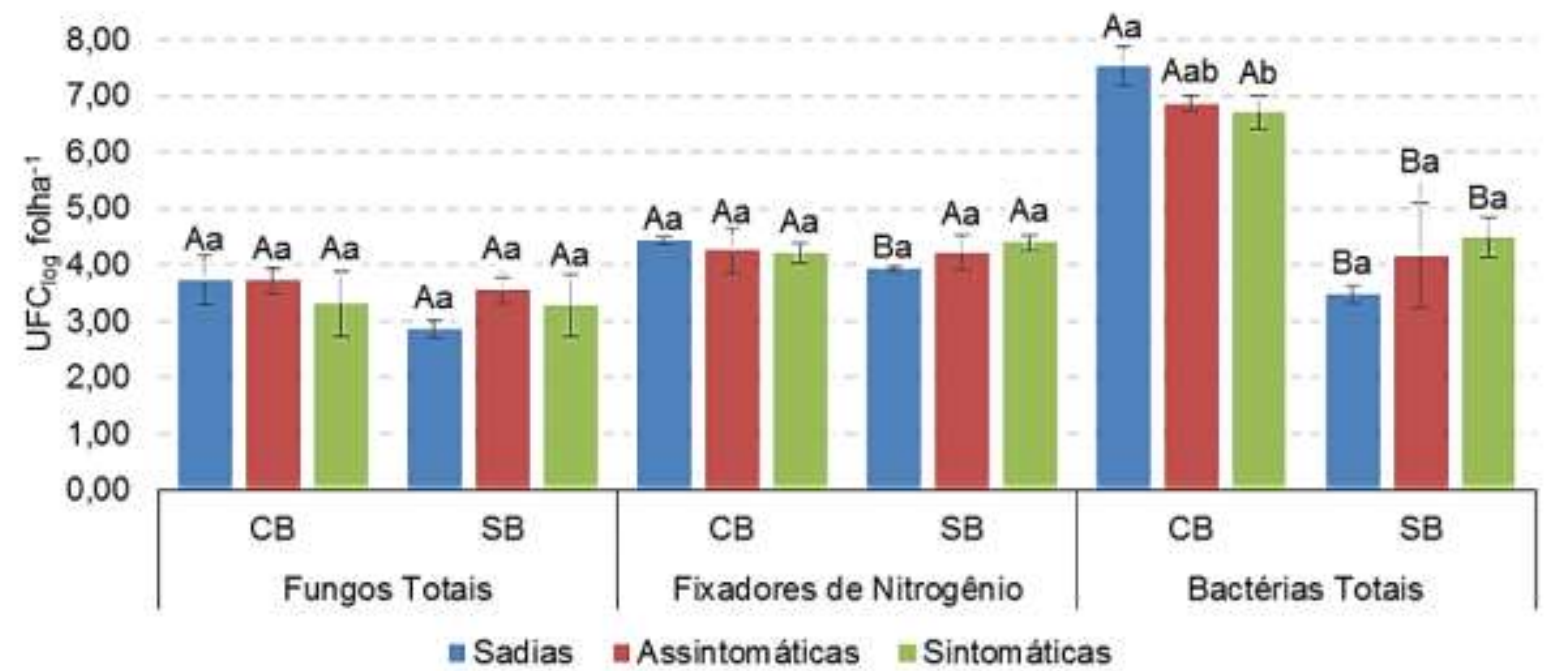

Letras maiúsculas e minúsculas iguais representam valores sem diferença significativa entre as áreas e entre as plantas, respectivamente, por teste de Tukey $(\mathrm{p}<0,05)$. Fonte: Autoria própria.

Os fixadores de nitrogênio foram encontrados em maior quantidade na área com biofertilizante, quando avaliadas plantas sadias. As demais categorias de plantas apresentaram a mesma quantidade de UFC para esta comunidade.

A comunidade bacteriana encontrada na superfície das folhas na área CB sofreu pequena redução em plantas doentes, porém, o número de bactérias totais foi expressivamente maior na área com aplicação de biofertilizante, seja em plantas sadias, assintomáticas ou sintomáticas.

Apesar deste estudo não fornecer informações a respeito da diversidade de bactérias, sabe-se que manejo adotado em um pomar de citros altera a estruturação e diversidade de bactérias associadas à filosfera, conforme constatado por Carvalho et al. (2020) após estudos comparativos entre manejo convencional e manejo ecológico, no qual a aplicação de agroquímicos é reduzida. Diferenças na diversidade da comunidade bacteriana em função do genótipo do hospedeiro também foram observadas em ramos de oliveira sintomáticos e assintomáticos em estudos quanto a relação entre a microbiota da filosfera e o 
patógeno Pseudomonas savastanoi pv. savastanoi (Mina et al., 2020). Isto indica que as interações entre as plantas, os microrganismos benéficos e os patógenos não depende apenas de um fator.

Assim, espera-se que as plantas na área CB sejam mais tolerantes à presença do HLB, por possuírem uma comunidade epifítica maior, conforme já observado em estudos com cacau (Theobroma cacao L.), nos quais Rubini et al. (2005) conseguiram identificar e isolar espécies de fungos endofíticos que apresentaram potencial para biocontrole de Crinipellis perciniosa, o agente causal da doença vassoura de bruxa. Dentre os isolados, Gliocladium catenulatum foi capaz de reduzir em $70 \%$ a incidência de vassoura de bruxa em mudas de cacau.

Resultados promissores também foram observados por Araújo et al. (2002). Os autores constataram que Curtobacterium flaccumfaciens foi mais frequente em plantas de citros assintomáticas quanto à clorose variegada dos citros, evidenciando o papel dessa bactéria na resistência à Xylella fastidiosa. Por outro lado, Methylobacterium spp foram altamente associadas à maior ocorrência e intensidade de sintomas de CVC. Essa mesma espécie também pode estar relacionada com o aumento de HLB (Zhang et al., 2013). Nan et al. (2021) observaram alterações fisiológicas benéficas em plantas infectadas por $C a$. L. asiaticus após a inoculação de Bacillus amyloliquefaciens $G J 1$, um isolado bacteriano previamente obtido de plantas com HLB. Dessa forma, o estudo de comunidades microbianas de citros com HLB pode elucidar como microrganismos da filosfera respondem ao desenvolvimento da doença, e podem inclusive revelar candidatos com potencial para controle biológico.

\section{Considerações Finais}

A aplicação de biofertilizante é capaz de aumentar a comunidade bacteriana epifítica em citros.

Estudos futuros devem ser conduzidos para verificar se há relação entre a aplicação de biofertilizante e a produtividade de árvores de citros sadias, além de realizar a comparação de riqueza, abundância e diversidade de bactérias em árvores sadias, assintomáticas e sintomáticas. Futuramente, podem ser realizados, a partir de material vegetal, o isolamento e identificação de espécies de bactérias com potencial antagonista ao huanglongbing.

\section{Agradecimentos}

Este estudo foi possível graças ao incentivo acadêmico da Coordenação de Aperfeiçoamento de Pessoal de Nível Superior, a Fundação Araucária pelo apoio Financeiro para publicação e ao CNPq com a concessão de bolsa.

\section{Referências}

Araújo, W. L., Marcon, J., Maccheroni, W., Van Elsas, J. D., Van Vuurde, J. W. L. \& Azevedo, J. L. (2002). Diversity of Endophytic Bacterial Populations and Their Interaction with Xylella fastidiosa in Citrus Plants. Applied and Environmental Microbiology, 68 (10), 4906-4914. https://doi.org/10.1128/AEM.68.10.4906-4914.2002

Backman, P. A. \& Sikora, R. A. (2008). Endophytes: An emerging tool for biological control. Biological Control, 46 (1), 1-3. https://doi.org/10.1016/j.biocontrol.2008.03.009

Bassanezi, R. B., Lopes, S. A., de Miranda, M. P., Wulff, N. A., Volpe, H. X. L., \& Ayres, A. J. (2020). Overview of citrus huanglongbing spread and management strategies in Brazil. Tropical Plant Pathology, 45, 251-264. https://doi.org/10.1007/s40858-020-00343-y

Belasque Junior, J., Yamamoto, P. T., De Miranda, M. P., Bassanezi, R. B., Ayres, A. J. \& Bové, J. M. (2010). Controle do huanglongbing no Estado de São Paulo, Brasil. Citrus Research \& Technology, 31 (1), 53-64. http://doi.org/10.5935/2236-3122.20100005

Boscariol-Camargo, R. L., Cristofani-Yaly, M., Malosso, A., Colettafilho, H. D. \& Machado, M. A. (2010). Avaliação de diferentes genótipos de citros à infecção por Candidatus Liberibacter asiaticus. Citrus Research \& Technology, 31 (1), 85-90. http:// doi.org/10.5935/2236-3122.20100008

Carvalho, C. R., Dias, A. C., Homma, S. K., \& Cardoso, E. J. (2020). Phyllosphere bacterial assembly in citrus crop under conventional and ecological management. PeerJ, 8, e9152. https://doi.org/10.7717/peerj.9152 
Döbereiner, J. \& Day, J. M. (1976). Associative symbioses in tropical grasses: characterization of microorganisms and dinitrogen-fixing sites. In: Proceedings of the 1st international symposium on nitrogen fixation. Washington State University Press Pullman, 2, 518-538.

Feichtenberger, E., Bassanezi, R. B., Spósito, M. B. \& Belasque, J. R. J. (2005). Doenças de citrus. In: Kimati, H., Amorim, L., \& Camargo, L. E. (Ed.). Manual de Fitopatologia (pp. 239-269). São Paulo: Editora Ceres.

Gottwald, T., Da Graça, J. V. \& Bassanezi, R. B. (2007). Citrus huanglongbing: The pathogen and its impact. Plant Health Progress. 8 (1), 31. https://doi.org/10.1094/PHP-2007-0906-01-RV

Kim, J. S., Sagaram, U. S., Burns, J. K., Li, J. L. \& Wang, N. (2009). Response of Sweet orange (Citrus sinensis) to 'Candidatus Liberibacter asiaticus' infection: microscopy and microarray analyses. Phytopathology, 99 (1), 50-57. https://doi.org/10.1094/PHYTO-99-1-0050

Mahajan, M. V., Jagtap, G. P. \& Dey, U. (2013). Rapid molecular detection of Candidatus Liberibacter asiaticus, the bacterium associated with citrus huanglongbing (greening) disease of Mandarin using polymerase chain reaction. African Journal of Biotechnology, 12 (29), 4623-4629. https://doi.org/10.5897/AJB12.1881

Medeiros, M. B. \& Lopes, J. S. (2006). Biofertilizantes líquidos e sustentabilidade agrícola. Bahia Agrícola, 7(3), 24-26. http://www.seagri.ba.gov.br/content/biofertilizantes-1\%C3\%ADquidos-e-sustentabilidade-agr\%C3\%ADcola

Mina, D., Pereira, J. A., Lino-Neto, T., \& Baptista, P. (2020). Impact of plant genotype and plant habitat in shaping bacterial pathobiome: a comparative study in olive tree. Scientific reports, 10(1), 1-11. https://doi.org/10.1038/s41598-020-60596-0

Mourão Filho, F. D. A. A., Stipp, L. C. L. \& Mendes, B. M. J. (2010). Perspectivas da produção e utilização de transgênicos para o controle do huanlongbing. Citrus Research \& Technology, 31 (1), 91-100. https://doi.org/10.5935/2236-3122.20100009

Nan, J., Zhang, S., \& Jiang, L. (2021). Antibacterial Potential of Bacillus amyloliquefaciens GJ1 against Citrus Huanglongbing. Plants, 10(2), 261. https://doi.org/10.3390/plants10020261

Qiu, M., Zhang, R., Xue, C., Zhang, S., Li, S., Zhang, N. \& Shen, Q. (2012). Application of bio-organic fertilizer can control Fusarium wilt of cucumber plant by regulation microbial community of rhizosphere soil. Biologic Fertility Soils, 48 (7), 807-816. https://doi.org/10.1007/s00374-012-0675-4

Rubini, M. R., Silva-Ribeiro, R. T., Pomella, A. W. V., Maki, C. S., Araújo, W. L., Dos Santos, D. R. \& Azevedo, J. L. (2005). Diversity of endophytic fungal community of cacao (Theobroma cacao L.) and biological control of Crinipellis perniciosa, causal agent of witches' broom disease. International Journal of Biological Sciences, 1 (1), 24-33. https://doi.org/10.7150/ijbs.1.24

Sauer, A. V., Zanutto, C. A., Nocchi, P. T. R., Machado, M. A., Bock, C. H. \& Nunes, W. M. C. (2015). Seasonal variation in populations of 'Candidatus Liberibacter asiaticus' in citrus trees in Paraná State, Brazil. Plant Disease, 99 (8), 1125-1132. https://doi.org/10.1094/PDIS-09-14-0926-RE

Shen, Z., Ruan, Y., Wang, B., Zhong, S., Su, L., Li, R. \& Shen, Q. (2015). Effect of biofertilizer for suppressing Fusarium wilt disease of banana as well as enhancing microbial and chemical proprieties of soil under greenhouse trial. Applied Soil Ecology, 93, 111-119. https://doi.org/10.1016/j.apsoil.2015.04.013

Silva, A. F; Pinto, J. M; França, C. R. R. S; Fernandes, S. C; Gomes, T. C. A; Silva, M. S. L. \& Matos, A. N. B. (2007). Preparo e uso de biofertilizantes líquidos. Embrapa Semi-Árido. Comunicado técnico 130. https://www.infoteca.cnptia.embrapa.br/infoteca/handle/doc/153383

Timmusk, S., West, P.V., Gow, N.A.R. \& Huffstutler R.F. (2009). Paenibacillus polymyxas antagonizes oomycetes plant pathogens Phytophthora palmivora and Pythium aphanidermatum. Journal Applied Ecology, 106 (5), 1473-1481. https://doi.org/10.1111/j.1365-2672.2009.04123.x

Trivedi, P., He, Z., Van Nostrand, J. D., Albrigo, G., Zhou, J. \& Wang, N. (2012). Huanglongbing alters the structure and functional diversity of microbial communities associated with citrus rhizosphere. International Society for Microbial Ecology Journal, 6 (2), 363-83. https://doi.org/10.1038/ismej.2011.100

Wu, H, Yang, X., Fan, J., Miao, W., Ling, N., Xu, Y., Huang, Q. \& Shen, Q. (2009). Supression of Fusarium wilt watermelon by a bio-organic fertilizer containing combinations of antagonistic microrganisms. Biological Control, 54 (2), 287-300. https://doi.org/10.1007/s10526-008-9168-7

Zhang, M., Powell, C. A., Benyon, L. S., Zhou, H. \& Duan, Y. (2013). Deciphering the bacterial microbiome of citrus plants in response to 'Candidatus Liberibacter asiaticus'-infection and antibiotic treatments. PLoS One, 8 (11), e76331. https://doi.org/10.1371/journal.pone.0076331

Zhang, S., He, X., Zhang, J., Raza, W., Yang, X., Ruan, Y., Shen, Q. \& Huang, Q. (2014). Supression of Fusarium wilt of banana with application of bioorganic fertilizers. Pedosphere, 24 (5), 613-624. https://doi.org/10.1016/S1002-0160(14)60047-3 